\title{
La circulación de las noticias en España a finales del siglo XVI. Relaciones de sucesos de Rodrigo de Cabrera (1595-1600) sobre las guerras turcas'
}

\author{
Carmen EsPejo CALA \\ carmenes@us.es \\ Universidad de Sevilla
}

Recibido: 2 de junio de 2014

Aceptado: 9 de diciembre de 2014

\section{Resumen}

Pretendemos analizar cuáles eran los cauces por los que circulaba la información durante la Edad Moderna. Nuestra hipótesis es que en la última década del XVI el sistema informativo europeo estaba lo suficientemente engrasado como para que las prácticas dispersas de los años anteriores catalizaran en una actividad comercial, y era ya tan eficaz como para que las noticias de un extremo de Europa -Transilvania- llegaran hasta el otro confín -Sevilla-. El trabajo se basa en el estudio del corpus de relaciones de sucesos en torno a la guerra contra el Turco publicadas por el impresor Rodrigo de Cabrera, primera serie periodística en España (1595-1600). Hemos aportado nuevos impresos a la serie hasta ahora desconocidos y hemos descubierto la fuente en la que se basaban sus noticias.

Palabras clave: Relaciones de sucesos, Noticias, Rodrigo de Cabrera, Guerra contra el Turco, Edad Moderna.

\section{News Circulation in Spain at the End of the Sixteenth Century.}

News Books by Rodrigo de Cabrera (1595-1600) on the War Against the Turks

\begin{abstract}
This paper looks into the circulation of information routes during Early Modern period. Our hypothesis is that in the last decade of XVIth century, European information system was rather sophisticated so as to conduit the dispersed practices of previous years into a solid business, and was sound enough for news being transmitted all across Europe from one of its ends, Transylvania, to the other, Seville. The paper is based on the study of the news books on the war against the Turks published by printer Rodrigo de Cabrera, first journalistic series in Spain (1595-1600). To this series, we have added some news sheets unknown till the moment and have found out the source of the news.
\end{abstract}

Keywords: News books, News, Rodrigo de Cabrera, War against the Turks, Early Modern period.

\section{Referencia normalizada}

ESPEJO CALA, Carmen (2015): "La circulación de las noticias en España a finales del siglo XVI. Relaciones de sucesos de Rodrigo de Cabrera (1595-1600) sobre las guerras turcas". Estudios sobre el Mensaje Periodístico. Vol. 21, Núm. 1 (enero-junio), págs.: 89-103. Madrid, Servicio de Publicaciones de la Universidad Complutense.

Sumario: 1. Introducción. 2. Transilvania en el foco del primer periodismo europeo. 3. La conexión italiana. 4. Juan de Mosquera: el relacionero en su red. 5. Desde Transilvania a Perú. 6. Conclusiones. 7. Referencias bibliográficas.

1 Este trabajo se inscribe en las labores de difusión del proyecto de investigación «Biblioteca Digital Siglo de Oro III», código FFI2009-08113 (subprograma FILO) cofinanciado por el INIA, en el marco del Plan Nacional de Investigación Científica, Desarrollo e Innovación Tecnológica (I+D+i) y el Fondo Europeo de Desarrollo Regional (FEDER). 


\section{Introducción}

Entre los hechos que fueron noticia para toda Europa, en los primeros tiempos de la Edad Moderna, se encuentra la guerra contra los turcos en la frontera Este. En España concretamente, un conjunto de relaciones de sucesos en torno a este tema está considerado como la primera muestra de actividad periodística en la plena acepción del término: se trata de las relaciones que publicó el impresor sevillano Rodrigo de Cabrera entre 1595 y 1600 acerca de las hazañas del Príncipe de Transilvania, Segismundo Báthory, y otros paladines cristianos contra los infieles. Este es el primer grupo de relaciones de sucesos en las que, si bien no se consolida una periodicidad concreta, sí se inscribe cada uno de los números en una serie semi-periódica, e incluso en algunos de ellos el título refleja esta intención con la inclusión de ordinales: segunda, tercera, cuarta..., hasta octava relación de sucesos en torno a la misma noticia.

En este trabajo hemos revisado exhaustivamente este corpus, y hemos conseguido aumentar el número de las relaciones incluidas en él. Gracias a la localización de fondos poco conocidos hasta ahora ${ }^{2}$, hemos podido concluir que son 30 las relaciones que conservamos de entre las que Rodrigo de Cabrera publicó en Sevilla sobre la guerra turca. Esto nos ha permitido por cierto añadir a las conclusiones algún pequeño hallazgo historiográfico, como lo es el hecho de que el impresor sevillano, al que la mayoría de las monografías dan por muerto en 1599, deba considerarse en activo al menos hasta 1600, fecha de la última relación suya que hemos encontrado.

Pero los objetivos de nuestro trabajo van más allá y pretenden determinar cuáles eran los cauces por los que circulaba la información en estos primeros momentos de la Modernidad. Nos preguntaremos en él por tanto sobre las formas o formatos (impresas, manuscritas...) con que circulaban las noticias; sobre el ritmo (periodicidad, demora con respecto a los hechos...) con que lo hacían; sobre la infraestructura que las acarreaban -los correos-, y, fundamentalmente, sobre los agentes -las personasque asumieron de manera profesional o semi-profesional la tarea de la información. Nuestra hipótesis de partida es que ya en la última década del XVI el sistema informativo europeo estaba lo suficientemente engrasado como para que las prácticas dis-

2 El conjunto más importante de impresos de Rodrigo de Cabrera en torno a las guerras turcas se encuentra depositado en la Real Academia de la Historia en Madrid. También conserva un conjunto importante la Biblioteca Universitaria de Sevilla. Estos fondos y otros con menor cantidad de ejemplares habían sido descritos en repertorios y catálogos desde principios del siglo XX en adelante: Uriarte (1906) describe 16 impresos en la serie; Agulló (1966) describe 20 y Domínguez Guzmán (2012) relaciona 24. En los últimos años, el Catálogo Colectivo del Patrimonio Bibliográfico Español ha incluido algunos registros más, correspondientes a la misma serie sobre las guerras en la frontera turca, de los que no se tenía noticia previa. Estos registros recogen los fondos depositados en la Academia de Ciencias Morales y Políticas de Madrid, llegados allí gracias a la donación post-mortem de D. Francisco de Cárdenas y Espejo, presidente de la Academia fallecido en 1898, ilustre político y erudito sevillano, que donó su nutrida biblioteca a la Academia. Nuestros impresos se encuentran en un volumen formado por 253 documentos impresos y manuscritos, todos ellos de Sevilla, con el título genérico de Relaciones históricas originales desde 1588 hasta 1631. Agradezco a D. Pablo Ramírez, Bibliotecario de la Real Academia de Ciencias Morales y Políticas, la ayuda prestada. 
persas de los años anteriores catalizaran en una actividad comercial sólida que consigue seducir definitivamente a su público. Este sistema era ya lo suficientemente eficaz y flexible como para que las noticias de un extremo de Europa -Transilvaniallegaron hasta el otro confín de la misma -Sevilla, en el sur de España- y viajaran incluso hasta la lejana América.

Nuestro trabajo pretende ser por tanto una pequeña aportación a la microhistoria del primer periodismo de la Edad Moderna en España y Europa. Admitimos dos limitaciones importantes: la imposibilidad de contar con el corpus total de lo publicado -teniendo en cuenta que muchos impresos deben haberse perdido-, y la dificultad para acceder a algunos de los conservados, lo que no nos ha permitido estudiarlos de visu. Esto hace que todo lo que sigue tenga cierto carácter de provisionalidad y deba ser entendido por tanto más como hipótesis de trabajo que como conclusión definitiva.

\section{Transilvania en el foco del primer periodismo europeo}

Nuestra pequeña o micro historia del periodismo comienza en Sevilla, en 1595, cuando Rodrigo de Cabrera publica la primera relación de sucesos sobre la guerra contra los turcos. Se trata de una Carta de Mahomet Tercer Emperador de los Turcos, escripta al Serenissimo Segismundo Batori, Principe de Transilvania, Moldavia, Valachia, \&c. Traducida de lengua Turquesca en Lengua Italiana en Roma, en la Estampa del Gabia, en el Año de Mil y quinientos y noventa y cinco, en una sola hoja. Si efectivamente ésta es la primera relación aparecida en el mercado sevillano ${ }^{3}$, debió sorprender bastante a sus lectores, porque la carta carece de preámbulo o de cualquier otro elemento paratextual que permita al lector saber quiénes son los corresponsales, emisor y receptor de la carta, y en qué hechos andan involucrados. Sin embargo debió tener un éxito rotundo, porque en el año siguiente de 1596 el mismo impresor publicó al menos seis relaciones más sobre el tema, además de reeditar la carta. En las licencias que se recogen al final de cada uno de estos impresos, se indica que dicha licencia se otorga en forma de privilegio por un tiempo creciente: un mes para el primer y segundo impresos de la serie, dos meses para el tercero, tres meses para el cuarto...;

3 No nos queda claro si la primera impresión de la Carta es del año 1595 o 1596. La fuente bibliográfica más antigua sobre este fondo, la de Uriarte, indica que "hay otra ed. muy parecida, también de un pliego en fol $^{\circ}$., pero con algunos cambios de ortografía en la misma portada y colofón" (Uriarte, 1906: 100), pero no especifica la fecha de esa otra edición. La fecha 1595 de deduce del título, aunque la que, según creemos, es la única edición que conservamos del impreso, es de 1596. La que nosotros hemos consultado, y a la que puede accederse en el enlace http://fondosdigitales.us.es/fondos/libros/900/1/carta-de-mahomettercer-emperador-de-los-turcos-escripta-al-serenissimo-sigismundo-batori-principe-de-transilvania/, obtuvo licencia en junio de 1596. En otra relación posterior de la serie, la Relacion de todo el cerco de Temesuar..., el colofón indica que Rodrigo de Cabrera obtuvo licencia para reimprimir la Carta en octubre de 1596. El aviso italiano que muy probablemente sirve como fuente para esta relación está fechado efectivamente en 1595: Lettera di Mahvmet III. Imperator de' Turchi, scritta al Sereniss. Sigismondo Battori Principe di Transiluania, Moldauia, Valachia, \&c. Tradotta di lingua turchesca in lingua italiana. Data in Constantinopoli il primo della Luna d'Ottobre 1595. In Roma, Nella Stâpa del Gabbia, 1595. 
luego el impresor debía temer que, en aquellos tiempos de piratería fácil, le robaran su exitoso tema.

Las razones por las que esta zona de Europa acapara la actualidad informativa por entonces las conocemos: Transilvania, epicentro de la mayor parte de las noticias, que forma parte a finales del XVI del Reino de Hungría, es un principado del Imperio del Sacro Imperio Romano Germánico que está bajo dominio de los Habsburgo, la misma dinastía que reina en España; el príncipe de Transilvania está casado con María Cristina de Habsburgo. En el momento en el que comienza la historia y desde 1526 Transilvania está parcialmente ocupada por los turcos, en una de las muchas acometidas de éstos contra los territorios cristianos. Desde 1538 los turcos ocupan también Moldavia, y en 1541 toman Buda y Pest. Nuestro príncipe de Transilvania, Segismundo Báthory, desde 1591 se ha integrado en una Santa Liga contra los turcos, encabezada por los Habsburgo, que pretende recuperar estos territorios, en la llamada "Guerra Larga" o "de los 15 años" (1591-1606) o "de los trece años" (1593-1606). Es probable que el mismo Báthory estuviera interesado en filtrar noticias favorables a su reputación, teniendo en cuenta los problemas internos que lo enfrentaban a la propia nobleza del lugar y que le obligaron a renunciar al trono en tres ocasiones.

Ahora bien, la estrategia informativa no hubiera podido materializarse si no se hubiera contado por entonces, en Europa, con la infraestructura suficiente que hiciera posible el movimiento de las noticias desde la frontera Este hasta las ciudades de Occidente, incluso las más lejanas como Sevilla. La década de los '90 del siglo XVI se ha señalado como el momento inicial de la potente red comunicativa que cubre Europa, gracias al establecimiento de las postas del correo internacional; en 1580 este red queda establecida por lo que respecta a los territorios de los Austrias de España, y engloba a Sevilla como punto más meridional. Consecuentemente la de los '90 fue una buena década para el desarrollo del periodismo no sólo en España, sino también en otros lugares y seguramente por las mismas razones: son las fechas, por ejemplo, en las que da comienzo en Colonia la publicación del Mercurius Gallobelgicus, o en las que en Inglaterra el impresor John Wolfe publica una serie de hojas de noticias semiperiódicas, Chiefe Occurrences, identificadas por Raymond (2003: 108) como "the first British periodical newspaper" en razón del mismo componente de serialidad que nosotros hemos destacado en la obra de Rodrigo de Cabrera.

Pero todavía éstas son razones muy generales para explicar cómo fue posible que un modesto impresor sevillano contara con información suficiente como para estar vendiendo a su público, con cierta regularidad, noticias impresas sobre el tema durante cinco años consecutivos. Pondremos el foco a partir de este momento, por tanto, en la pequeña red en la que se mueve nuestro impresor y que permite el pequeño logro de la aparición del periodismo en Sevilla.

\section{La conexión italiana}

La primera de las incógnitas que suscita esta colección se refiere a las fuentes de información con las que cuenta el humilde impresor sevillano para urdir su serie periodística. Nuestra pesquisa nos ha permitido descubrir que la materia fundamental de los relatos de Cabrera son una extensa serie de avisos impresos italianos, los publicados 
por al menos dos novellanti italianos. De hecho, los mismos textos de Cabrera lo confiesan así: la Carta de Mahomet... indica como hemos visto en su título "Traducida de lengua Turquesca en Lengua Italiana en Roma"; y la Qvarta parte dela relación... indica en el colofón "Impresso en Roma con licencia de los Superiores. Y ahora en Sevilla con Licencia". Es más, los nombres de estos reportisti que sirven de fuente están declarados en los encabezamientos de tres de las relaciones de Cabrera:

Aviso del Aparato de la pompa y del numero de soldados con que Mehemet Rey de Turcos partio de Constantinopla para yr a la guerra de Vngria a los 20 de Iunio de 1596. Publicado por Bernardino Becheri, de Savile, a la Minerva, con licencia de los superiores en Roma, por Nic. Mutio, 1596.

Octava relacion y nuevos avisos de Alvaivlia, De primero de Mayo, deste Año de 1597. [...] Publicadas en Roma por Bernardino Becari a la Minerva. E impressas en Roma en la imprenta de Nicolas Mucio. En el dicho Año. Y por el mismo original sacadas de Italiano, en nuestro vulgar Castellano, en este mes de Iulio a veinte días del, y del dicho año.

La prometida de la vitoria qve los capitanes del Emperador vvieron de los Tvrcos en el Danubio a los Veinte y vno de junio, deste presente Año de Nouenta y nueue. Publicados en Roma por Geronymo Acolto con licêcia de los Superiores en casa de Nicolas Mucio [...]. En este Año de 1599. Trasladado de Italiano bien y fielmente en nuestro vulgar Castellano.

Los dos relacioneros italianos nombrados son Bernardino Beccari y Girolamo Accolti. Ahora bien, puesto que justamente de una de estas relaciones no se conserva ejemplares y otras dos están entre aquellas que hasta ahora eran prácticamente desconocidas, por estar conservadas en fondos accesibles desde hace poco tiempo, ningún investigador había reparado en el hecho de que los textos de Cabrera traducen textos italianos previos de Beccari o Accolti.

Aunque por el momento son muy pocos los originales italianos que hemos podido leer, más adelante en este mismo trabajo avanzaremos las conclusiones de un cotejo textual exhaustivo. Basándonos simplemente en la casi literalidad con la que los títulos de los impresos españoles traducen los títulos italianos, podemos afirmar que la mayor parte de las relaciones de Rodrigo de Cabrera parecen estar basadas en traducciones de avisos de Bernardino Beccari, y en menor medida traducen avisos de Accolti. Un par de ejemplos bastarán para probar la estrecha relación entre estos títulos: la Qvarta parte dela relación nveva, De Transilvania y Valachia, Por la qual se avisan los prosperos sucessos del Serenissimo Principe de Transilvania contra los Turcos, assi en el vn Reyno, como en el otro despues de la venida de la Corte del Emperador; desde primero de Mayo de 96, parece hacer derivar su título del impreso de Beccari Aunisi nuoui di Transiluania et di Vallachia per li quali s'intendono li prosperi successi del sereniss. principe contra turchi, impreso en el mismo año de 1596.

Esta relación contiene además en su interior una noticia a la que se da un encabezamiento diferente, Nueva de la Rota hecha, de la gente de el Serenissimo principe de Transilvania a los Turcos y Tartaros junto a la Lippa con muerte de ocho mil de los Turcos y presa de tres Vchies, y toma de la Artillería y Vagajes, y de aver alçado el cerco; cuyo título permite pensar que se basa en el original de Beccari Auuisi della rotta data dalle genti del sereniss. prencipe di Transiluania ai turchi, \& tartari a 
Lippa, con morte di ottomila di essi, presa di tre Behì, \& acquisto d'artiglierie, stendardi, bagaglie, \& leuata dell'assedio. Con altri aunisi nuoui di Valacchia.

Estos periodistas italianos por tanto llegaron a tener una sorprendente proyección internacional, y sus reportajes se tradujeron o copiaron a muchas leguas de distancia. Sabemos poco de Girolamo Accolti: tan sólo su condición de maestro de escuela y autor de avisos impresos publicados en Roma.

Sabemos algo más de Bernardino Beccari. Beccari es un librero, editor y periodista italiano de la segunda mitad del XVI. Los datos biográficos que conocemos lo consideran nacido en Sacile, en la por entonces Marca Trevigiana, y por lo tanto muy cercano a Venecia, núcleo fundamental en la conexión entre Occidente y Oriente. En 1575 es autorizado a abrir una librería en la plaza de la Minerva de Roma. Según indica Bulgarelli, se le recuerda sobre todo como autor de numerosos opúsculos noticieros, es decir, como redactor de avisos impresos, publicados en su mayor parte en la imprenta romana de Nicolò Muzi. Bulgarelli señala también que, a pesar de que el historiador del XVIII Mazzuchelli lo registra como autor de once avisos entre los años 1595 y 1599, el dato es incorrecto, pues tan sólo en las bibliotecas romanas se conservan más de cincuenta ejemplares de avisos de Beccari. Nosotros mismos, tras una rápida pesquisa, hemos localizado hasta 53 opúsculos tan sólo entre los dedicados a las guerras cristiano-turcas de finales del XVI y principios del XVII. Bulgarelli (1970) lo considera "el precursor del periodista italiano.

Aunque escribió avisos sobre diversos temas de la actualidad internacional de la época, su especialidad fueron sin duda las noticias sobre el conflicto con los turcos en Los Balcanes. Empieza a interesarse por el tema en 1593, justo en el momento en el que estalla la "Guerra de los Trece Años", o al menos de esa fecha son los avisos impresos sobre cualquier tema más antiguos que le conocemos. En este año escribe al menos dos avisos impresos, de uno se conserva copia en Roma (imprenta de Luigi Zannetti) y de otro en Roma y Nápoles. Uno de ellos se denomina Auiso d'vna rotta data dalle genti di sua maesta cesarea..., de manera que emplea en su título el nombre con el que será reconocido en toda Europa este primer género periodístico de la Edad Moderna, aviso. Aunque no es la única denominación con la que titula sus opúsculos, sí es la más recurrente en su producción.

Del año siguiente, 1594, conocemos otros tres avisos impresos de Beccari, sobre el mismo conflicto en Los Balcanes y también publicados en la imprenta romana de Zanetti; de uno de ellos, Auisi nuoui della rotta data dal general superiore al beglierbei della Grecia..., se publicó una versión en Verona, y el impreso de ésta indica a su vez que hubo también reimpresión del mismo en Bolonia. No cabe duda entonces que los avisos de Beccari tuvieron éxito inmediato y circularon extensamente por Italia.

Ahora bien, la explosión informativa llega al año siguiente, 1595 -el año en el que Báthory firma un tratado con la Liga Santa-, cuando Beccari publica al menos quince impresos en torno a la noticia que nos ocupa. De éstos, dos impresos reproducen sendos discursos u orationes escritas por Girolamo Frachetta y destinados al príncipe cristiano de Transilvania, Segismundo Báthory, exhortándolo a continuar la guerra contra los infieles turcos. Recordemos que estos discursos u orationes fueron un género habitual en la escritura política de la primera Edad Moderna. 
Aunque no se trata en este caso de noticias como las concebimos en la actualidad, estas cartas resultan de interés para nuestra investigación porque quizás nos ayudan a reconstruir la red clientelar gracias a la cual las novedades sobre la frontera Este han podido llegar hasta Beccari y desde ahí, como veremos más adelante, a otros enclaves europeos. Hemos indicado que las cartas u orationes son obra de Girolamo Frachetta da Rovigo: este es un filósofo y escritor político, miembro de la Accademia degli Incitati romana; nuestro periodista Bernardino Beccari fue editor de al menos tres obras suyas, publicadas en la imprenta de Nicoló Muzi en Roma. Frachetta, escritor de cierta reputación por tanto, estuvo primero al servicio del Cardenal Luigi d'Este y luego de Scipione Gonzaga, cardenal y Patriarca de Jerusalén. Es posible que ambos dignatarios, y también el escritor Frachetta por encargo de éstos, correspondan al tipo de clientes asiduos de las redes de avisos manuscritos descritas por Infelise (2002). En nuestra hipótesis, éstos podrían ser los destinatarios últimos de los avisos manuscritos o impresos que llegan a Beccari desde la frontera. El reportista Beccari, relacionado con ese círculo puesto que editó las orationes de Frachetta, edita también e imprime las noticias sobre las guerras transilvanas a las que tiene acceso este círculo, seguramente con la anuencia del mismo.

Sea ésta o no la red a través de la cual le llegan las noticias, además de estas dos "oraciones", Beccari publica a lo largo de 1595 al menos trece impresos más sobre las guerras turcas. De ellos, la mayor parte se titula avvisi o avviso y uno sólo relatione; del mayor número de ellos encontramos reediciones o reimpresiones en otras ciudades italianas distintas a Roma, lo que confirma el éxito comercial de la serie. La fiebre informativa que desatan las peripecias del Príncipe de Transilvania y otros líderes militares cristianos parece desatarse en el verano de 1595, pues, según la información que aportan sus títulos, la mayor parte de estos impresos se publica entre últimos de junio y mediados de noviembre.

En los años siguientes Beccari seguirá publicando avisos sobre el mismo asunto: conocemos quince de 1596, cuatro de 1597, seis de 1598, seis de 1599 y dos de 1600 , año de la desaparición del autor.

\section{Juan de Mosquera: el relacionero en su red}

Localizados, entonces, algunos de los agentes de la micro-red que surte a Rodrigo de Cabrera, cabe preguntarse ahora cómo han llegado estos avisos italianos hasta las prensas del tipógrafo sevillano. La lectura atenta de los textos españoles nos permite concluir que el siguiente elemento en la red que lleva noticias desde Transilvania a Sevilla es un relacionero español que, residente de manera temporal en Roma, recibe regularmente los avisos impresos italianos, los traduce y los utiliza para construir sus propios relatos. Podemos aventurarnos a apuntar su nombre: Juan de Mosquera. De hecho, este nombre está también indicado por el mismo Cabrera, pero sólo en una de las relaciones, la tercera, que indica en su encabezamiento: Tercera Relacion de lo sucedido al Principe de Transiluania desde catorze de Março de noventa y seys hasta. 27, de Abril del dicho año [...]. Embiada por el hermano Iuan Mosquera para el padre Prouincial del Peru, su fecha en seys de Mayo de, 1596.

¿Quién es Juan de Mosquera? Con toda probabilidad se trata de un jesuita, Coadjutor de la orden, conocido en la bibliografía española por una obra extensa, Historia 
de este Colegio de la Compañia de Jesús de Madrid, dividida en II libros en los cuales se contienen las cosas memorables que han sucedido en él desde el año $1547 . .$. hasta el de 1600, que le fue encargada por el rector del Colegio de Alcalá de Henares. Según Domínguez Guzmán (2012: 183), llegó a ser copista del General de la Compañía, Claudio Acquaviva. Es pues tanto cronista como copista, y sabemos que ambos oficios estuvieron muy próximos al de periodista o relacionero en los primeros tiempos del periodismo europeo.

Los repertorios bibliográficos han otorgado valor desigual a esta información. Para Uriarte (1906), Mosquera es "traductor" de los impresos de Cabrera -aunque no se indica en su obra cuáles son los originales traducidos-. En el resto de las bibliografías o catálogos esta atribución se repite, y es habitual que se utilicen indistintamente las menciones a Mosquera como "traductor" y como "autor".

Pero todavía es necesario precisar el papel de Mosquera en la producción de las relaciones españolas sobre la guerra turca; determinar, para empezar, si se limitó a traducir los textos de Beccari, Accolti y quizás otros, o asumió una figura más compleja, la de periodista o editor periodístico. De la lectura atenta de los textos hemos concluido que la segunda opción es la más probable.

La comparación detallada entre los avisos de Beccari y las relaciones de Cabrera nos desvela los procedimientos a través de los que este último compone sus escritos. La Verdadera relacion de la insigne victoria qve Michael Bayboda (de la Balachia,) Capitan general del Serenissimo Principe de Transiluania a alcançado contra el Gran Turco... (1599) por ejemplo, tiene su fuente fundamental en el texto de Beccari Auuiso della rotta che ha data il vaiuoda di Valacchia alle genti del turco in Bulgheria, \& della presa di Nicopili capo di detto regno di Bulgheria... (1598). El aviso del italiano aparece efectivamente traducido, casi literalmente. Estas son por ejemplo las primeras íneas de uno y otro texto:

"Da tutte le parti mostra la Divina Misericordia di favorire la causa de' Christiani contra il Tiranno de Turchi, \& di combatter per noi, poiche, oltra di haver per mezo della peste (la qual tuttavia continua) fatto grandissima strage in Constantinopoli, d'ogni sorte di persone, fin ne i Serragli medessimi del Signore, dove sono morte più di quattro cento Persone...".

"La diuina Misericordia de Dios nuestro Señor por todas las partes, muestra que quiere fauorecer la causa de los Christianos contra el tirano del gran Turco, y que pelea por nosotros, pues demás de auer hecho grande estrago con la peste en Constantinopla, la qual no cessando continua, muriendo de todas suertes de personas, aun hasta en los mesmos Cerrallos del Turco, donde se an muerto mas de quatrocientas personas...".

Pero esta traducción ocupa poco más de una de las cuatro carillas del pliego de la relación española. En el título de ésta se avisa que, además de la noticia procedente de la fuente italiana, la relación relata "otros auisos de diuersas partes dignos de saber", y en efecto la primera página casi se dedica por completo a la recopilación de breves noticias procedentes de diversas fuentes, con la mención expresa de las mismas: "Por cartas escritas de veynteseys de Setiembre del año pasado de nouenta y ocho", "De Transiluania", "De Croacia", "Anda aquí en Roma impressa vna carta...", "De Paris por cartas de Octubre", "De Viena", "Que a la buelta de Baradino", "Por cartas de Paris de ocho de Octubre". También la última de las carillas del pliego, una vez trans- 
crito el aviso de Beccari, vuelve a incluir breves noticias de diversas fuentes: "Por carta de Ferrara", "De Transiluania se auisa". Además, en el verso de la primera página se incluye, presumiblemente traducida a partir del italiano también, una "Copia de vna carta de Roma de veintiocho de Nouiembre de. 1598".

El relacionero Mosquera trabaja entonces a partir de fuentes múltiples y compone su relato con notable autonomía; los avisos de Beccari, Accolti y seguramente otros menanti italianos le sirven como aportación inicial y probablemente también se utilizan como reclamo o como refuerzo de la credibilidad informativa, cuando se alude a ellos en los títulos de las relaciones.

La serie periodística, tanto si el primer número de la misma es la Carta de Mahomet como si lo es la Relacion de lo sucedido al Serenissimo Principe Sigismundo Batori..., comienza in media res, sin presentación o exordio alguno. En esta última relación, un redactor innominado presenta una serie de avisos sobre el conflicto con los turcos diciendo: "Ase dicho aquí en Praga...". Parece por tanto que Mosquera comienza su relato traduciendo las piezas italianas sin apenas intervención; pero ya en la siguiente relación, la titulada Segvnda Relacion De los hechos y Vitorias del Serenissimo Principe de Transilvania ..., encabeza el relato con un largo exordio en el que, aún sin firmar, aclara el contexto en el que se produce esta correspondencia: "Pax Christi. Dende el Março pasado de Noventa y cinco comencé a tomar por asumpto el escrevir a V.R. cada mes, las Proezas, Hazañas, y cosas milagrosas, que el Christianissimo Principe de Trâsilvania, assi por sus capitanes, como por su persona avia hecho è iva continuando contra los Turcos [...]".

La alusión al destinatario, identificado como "V.R." o "vras Reverencias", precisa el marco religioso en el que se van a leer las gestas de Báthory; la elección del protagonista se justifica según los intereses de la Compañía de Jesús: “...estimando en mas la gloria y servicio de Dios nuestro Señor y la anplificacion de su Santa Iglesia, de q da muchas señales cada dia, y no fue pequeña la q dio entrando el Lipa, en ordenar q lo primero q se hiziesse en aqlla ciudad, fuesse un Colegio de la Côpañia".

El resto de la serie oscila entre las dos posibilidades apuntadas: el grado cero de intervención por parte de Mosquera, que en algunos números parece limitarse a traducir los originales italianos; y la reedición total de los relatos originales, resumiendo, interpretando, forzando siempre la lectura providencialista que en cualquier caso estaba ya también en los originales de Bernardino Beccari.

En la Tercera Relacion de lo sucedido al Principe de Transiluania... Juan de Mosquera aclara las condiciones del compromiso que ha adquirido con su corresponsal: "Con el ordinario de Março escreui a V.R. y embiè los ultimos avisos que vinieron de Transiluania, agora no sabemos nada de alla, de que poder hazer larga relación. Pero dire en esta lo que uviere por no perder el curso de hazer esto cô todos los Correos...". Justamente, es en el encabezamiento de esta tercera relación en la que se ofrecen por vez primera y única los nombres de emisor y destinatario: "Embiada por el hermano Iuan Mosquera para el padre Prouincial del Peru". Luego este compromiso podría ser entendido como un gesto de pleitesía o vasallaje, y la información en sí -la cantidad o calidad de información de la que se dispone para ser relatada-, podría llegar a ser una cuestión secundaria. Si así fuera, esta serie de textos se enmarcaría en una práctica ha- 
bitual de las relaciones sociales y laborales de la primera Edad Moderna, y tendría poco que ver con la pasión por el periodismo que parece despertar en Europa por estas mismas fechas.

Sin embargo, en esta misma tercera carta de Mosquera, y ante la probable demora con la que llegan los avisos italianos que hasta ahora habían servido de fuente fundamental, el relacionero multiplica sus esfuerzos para obtener alguna información relevante: "Con el Correo de Viena desta semana escriue el Agente del Archiduque Maximiliano que por allí acabaua de passar una estafeta de Principe de Transiluania con nueva de que..."; "Por cartas de los nuestros de. 22. de Abril se tiene aviso...".

En los números que siguen, el redactor sigue acopiando fuentes diversas y contrastándolas entre sí para garantizar la veracidad, como hace en la Sexta relación...: "Vino esta nueva a Madrid por via de Venecia por muchas Cartas, y mexorose por via de Leon de Francia que dize lo mismo". El redactor procura disponer su relato, y el lapso entre las entregas del mismo, de manera que el lector no pierda el interés por el tema: "Despves de la Famosa, y memorable batalla de Agria, que fue a los 16. de Otubre, las cosas de la guerra, en Vngria, an estado muy quietas hasta agora", comienza diciendo en la Octava relación...

De esta manera, creemos que el cronista Mosquera se convirtió en un periodista consciente, y que incluso intuyó las posibilidades de futuro de la información periódica cuando tituló a sus cartas con ordinales: "segunda relación", "tercera relación", "cuarta parte de la relación", "quinta relación", "sexta relación", "relación séptima", "octava relación". Cabe preguntarse por qué abandonó los ordinales en este punto, cuando todavía seguiría escribiendo cartas con noticias sobre los turcos durante dos o tres años más: quizás porque a partir de este momento -mediados de 1597- Mosquera comienza a alternar relaciones monográficas sobre el conflicto transilvano con relatos que construye de acuerdo con un nuevo patrón, en el que se da cabida a noticias de diferente extensión y acerca de conflictos internacionales diversos, también a partir de diversas fuentes: en su caso, y además de la guerra contra los turcos, Mosquera introduce fundamentalmente información sobre conflictos diplomáticos entre los pequeños estados italianos y sobre la guerra contra franceses y flamencos. Este otro género -que por otra parte fue habitual en las prensas españolas a lo largo de todo el siglo- preludia el desarrollo de la gaceta en toda Europa, un par de décadas después.

El primer impreso de la serie de Mosquera que se ajusta al nuevo molde genérico refleja en su título su contenido heterogéneo: Relacion de lo svcedido en Frâcia, y Estados de Flandes, despues de la toma de Amiens: Y de lo que estos meses pasados a sucedido en la corte del Principe de Transilvania, del Emperador, y del grâ Turco. Lo qual se sabe por Cartas de Roma, de tres de Mayo de este presente año de mil y quinietos y noventa y siete. Este giro en su producción podemos interpretarlo de dos maneras. Es posible que Mosquera, a partir de su experiencia previa como narrador de las guerras turcas, fuera adquiriendo conciencia del valor de la información, y se convirtiera así en precursor del periodista, o quizás simplemente fue urgido por su correspondiente a ampliar el campo geográfico de sus noticias.

¿Fue entonces Mosquera único autor de todos los textos de Cabrera? No podemos asegurarlo en este punto de la investigación. De hecho, en al menos dos de las rela- 
ciones el impresor indica nuevos nombres: Rodrigo Olea de Ossisinaga y Agustino del $\mathrm{Olmo}^{4}$. No hemos conseguido encontrar información significativa sobre estos dos posibles relacioneros españoles; pero es posible que el impresor sevillano, a partir de 1597, una vez comprobado su éxito en el mercado, recurriera a todas las fuentes posibles sobre el tema, y que sean por tanto más de uno los autores cuyos textos reproduce en las relaciones impresas.

Reconocer la autoría, total o predominante, de Juan de Mosquera, nos permite también comprender el marco en el que tiene un sentido concreto este acopio de información sobre una guerra tan lejana. Hemos señalado que Juan de Mosquera es jesuita: precisamente esta condición suya explica la oportunidad de su correspondencia. Sabemos que la orden de la Compañía de Jesús tuvo entre sus muchas particularidades la de otorgar un valor señalado a la correspondencia entre sus miembros, entendida ésta como una prueba más de la obediencia debida a quienes precedían en la jerarquía. Las famosas "cartas de jesuitas" constituyen así un corpus ingente de documentación sobre hechos de actualidad que son fuente privilegiada para historiadores de todos los tiempos. Si, efectivamente, Mosquera se desempeñaba en Roma como copista al servicio del Superior Acquaviva, probablemente tuvo acceso a las cartas y demás información que llegaban a este.

Pero, más particularmente, la correspondencia entre el Hermano Coadjutor Juan de Mosquera y el Padre Provincial del Perú se explica porque justamente en 1595, fecha en la que empieza la correspondencia y también la publicación de relaciones impresas, la Orden había sido restablecida en Transilvania, y a juzgar por lo que leemos en estas mismas relaciones, gracias al afán católico de Segismundo Báthory. No fue fácil la implantación de la orden en Transilvania: los jesuitas fueron expulsados en 1598, y de nuevo permitidos en 1599 , pero lucharon siempre contra el rechazo de los protestantes de la región. En este inflamado clima religioso, las relaciones de Juan de Mosquera adquieren un nuevo sentido propagandístico, añadido al de la propaganda política que ya apuntábamos en las primeras líneas del trabajo.

Como ya hemos apuntado, los relatos de Mosquera están impregnados del providencialismo que es, por otra parte, tan habitual en el primer periodismo europeo, y en varias ocasiones se hace mención expresa de los intereses de los jesuitas. Pero, fundamentalmente, es una de las relaciones la que ofrece el marco de interpretación para toda la serie: en Relacion verdadera del linaje y descendencia del Serenissimo Sigismundo Batorio, Principe de Transiluania, Moldavia y Valachia, sacadas de historias autenticas, y relaciones muy verdaderas, venidas de aquellas partes, con algunas de

${ }^{4}$. El primero, que Domínguez Guzmán transcribe con ortografía moderna Olía de Osizenaga, es mencionado en el titulo Nuevos avisos venidos de Roma en este mes de Octubre a seys dias del. Y embiados a diez del mes passado de Agosto deste año de noventa y siete, por el Licenciado Rodrigo de Olea de Ossisinaga, al Padre Fray Alonso de aguilar, de la Orden de Sancto Domingo, a esta Ciudad de Sevilla. En que se da cuenta de las cosas que passan en Turquia. Y el segundo en Nuevas Que cuentan la Toma de Pappa, Fortaleza de Vngria ... Relacion del numero de los exercitos que se han de hallar en el Capo, en la Vngria, este presente Año en servicio dela Cesarea Magestad. Escripta por el Agustino del Olmo... 
sus hazañas y proezas dignas de gran memoria, Mosquera o quien fuera su autor aprovecha un lapso entre noticia y noticia para hacer un recordatorio de las hazañas y virtudes del príncipe, y entre ellos destaca fundamentalmente el establecimiento de la orden de los jesuitas en el conflictivo territorio transilvano: "La primera fue traer a los padres de la Compañía de Jesus a su Reyno...".

Juan de Mosquera pudo haber sido urgido por su correspondiente, el Provincial del Perú, a informarle periódicamente de los acontecimientos en Transilvania y otras partes del mundo, tal como por las mismas fechas se le demandó escribir la historia de la Compañía; o bien se trató simplemente de un gesto de vasallaje o de amistad, muy común como sabemos en la época. Esto no impide sin embargo que otorguemos una clara vocación periodística a Juan de Mosquera: según hemos visto antes, y si efectivamente él es el autor de todos o la mayoría de los textos, a menudo Mosquera se deja llevar por el afán divulgativo y las marcas del género epistolar se desdibujan en su relato. El primer periodismo nace a tientas y lo hace, según sabemos, modificando acervos textuales previos.

Estamos llegando por tanto casi al final de la micro-red que conecta Transilvania con Sevilla; creemos que, a la vista de lo que ya conocemos, es perfectamente posible que un jesuita avezado en la escritura histórica, residente en Roma, se dedicara a mantener una correspondencia sobre las guerras turcas con un superior, tomando como base para sus relatos las relaciones impresas italianas que llegan por correo, además de otros muchos avisos que llegan a través de este correo ordinario o a través de emisarios particulares. Su posición en la orden le permitiría el acceso a estas fuentes.

Debemos preguntarnos todavía qué formato tuvieron originalmente las cartas o relaciones de Mosquera. Como correspondencia particular que fueron -tuviera o no en mente Mosquera la posibilidad de la impresión-, es inevitable que circularan por correo y en la modalidad manuscrita. Se abre paso entonces el siguiente interrogante: ¿Cómo es posible que, con sólo unas pocas semanas de demora ${ }^{5}$, las conozcamos a través de versiones impresas, obra de un tipógrafo que trabaja en la lejana Sevilla?

\section{Desde Transilvania a Perú}

Es posible que la explicación para este último punto de nuestra pesquisa se encuentre en el otro extremo de la correspondencia sostenida por correo, su destinatario: el Padre Provincial del Perú. Este Padre Provincial del Perú, por las fechas en las que se publican los impresos que nos ocupan, era Juan Sebastián de la Parra, nacido en España y muerto dos décadas después en Lima. Había llegado al Perú en 1581 y fue provincial de la orden allí entre 1592 y 1599 , y después entre 1609 y 1616. Entre sus logros estuvo la introducción de la Compañía de Jesús en Chile. Por tanto, es en principio a Juan Sebastián de la Parra a quien se dirigen estos relatos, y, puesto que este reside en estas fechas en Perú, las cartas enviadas desde Madrid deben pasar necesariamente por Sevilla, donde se recopila la correspondencia que viaja hacia América, único puerto

5 Este dato se deduce del lapso de tiempo indicado entre el cierre de las cartas y la fecha en la que éstas obtenían la licencia, pues la práctica habitual era la impresión inmediata una vez obtenido este requisito legal. 
español autorizado para tal tráfico. No es difícil suponer que el impresor Rodrigo de Cabrera cuenta entre sus contactos con alguien cercano a los jesuitas -de hecho, se conoce su vinculación con estos desde muchos años atrás- que le permite tener acceso a esta correspondencia e imprimirla ${ }^{6}$. Recordemos que este tipo de comunicación sobre la actualidad política tenía carácter semi-público y la impresión de las cartas era una posibilidad no sólo frecuente sino también prevista por los correspondientes.

Nos cuesta algo más entender por qué un religioso establecido en las lejanas tierras de Perú requiere información tan continua y detallada de una guerra que sucede en el otro confín de la tierra. Lo poco que sabemos de Juan de la Parra no nos permite ver en él a un intelectual con profundas preocupaciones humanísticas: de hecho su fama entre los provinciales de la orden se debe a que promovió un estatuto de limpieza de sangre para discriminar a los nuevos ingresados en la orden en Perú, ante sus recelos al ver que indios y mestizos iban ascendiendo en la jerarquía? Pero es posible que la visión de un mundo global, que creemos privilegio de nuestros días, estuviera ya presente en el episteme de los hombres de la primera Modernidad, y que éstos leyeran las relaciones sobre guerras lejanas con la misma preocupación con la que nosotros hoy leemos las páginas de internacional de los periódicos.

En cualquier caso, el impresor sevillano Rodrigo de Cabrera tuvo acceso a un acopio de información prodigiosamente detallada, veraz, relevante, en torno a la Guerra de los Trece Años. A él corresponde la última actuación en esta micro-red que venimos describiendo; intentaremos en este último estadio del análisis determinar qué grado de intervención del impresor hay en la versión final impresa.

En la primera relación de la serie, la Relacion de lo sucedido al Serenissimo Principe Sigismundo Batori..., concluye con un colofón que muestra ya sus habilidades publicitarias: "Lo que succedio después desto, y los Genizaros que le a muerto al Turco, y fortalezas que a ganado, se queda imprimiendo, que es cosa digna de saberse". A partir de ahí, numerosas acotaciones incluidas en los colofones de los impresos permiten pensar que el impresor - si es efectivamente él quien los redacta- controla desde el principio el flujo, el ritmo, con el que la información sale al mercado sevillano.

Entre junio y octubre de 1596, y de acuerdo con las fechas de las licencias, imprimió al menos siete relaciones sobre el tema. Pero es posible que la extensión y arco cronológico cubierto por sus relatos no se correspondan con los de la información que, vía carta, le llega desde Roma. En el colofón de la Tercera relación ... dice: "Lo de Iunio y Iulio de 96. q prosigue tras esto se imprimirá luego, Fin", y siguen en orden cronológico en efecto dos impresos más que cubren los sucesos de esos meses: el primero, la Qvarta parte dela relación nveva ..., contiene de hecho dos relatos, a juzgar por sus títulos traducidos de avisos de Beccari, cada uno con su encabezamiento propio, comprimidos en un pliego. El segundo, es una breve relación que apenas cubre una hoja y

6 Domínguez Guzmán señala que su llegada a Sevilla, seguramente desde Madrid, se produce por llamado de los jesuitas, que le piden que funda para ellos unos tipos de imprenta, y señala también que entre las pocas obras extensas que se conocen del impresor figuran al menos dos de autoría jesuítica (2012: 176).

7 Véase Coello de la Rosa (2008). 
que relata tan sólo una batalla, a partir de una traducción de Beccari otra vez, según creemos. Nuestra hipótesis es que toda esta información, correspondiente a los meses de junio y julio de 1596, ha llegado en un solo envío a Cabrera, en una de las cartas de Juan de Mosquera, y es el impresor quien parcela las noticias para obtener una serie, seguramente cuasi periódica, con la que mantener expectante a su público ${ }^{8}$.

Finalmente: ¿cómo se explica el éxito en el mercado de esta extensa serie? La insistencia con la que Rodrigo de Cabrera solicita y da noticia explícita del privilegio obtenido, advierte a su público de próximas emisiones y publicita en general sus relaciones, nos permite imaginar a un público ávido de novedades, y quizás gratamente sorprendido por esta nueva modalidad editorial: la información periódica. Las vicisitudes en la frontera turca habían sido objeto años antes de un volumen extenso, los Commentarii della guerra di Transilvania de 1563, de Ascanio Centorio de gli Hortensii, que sabemos llegó a las librerías sevillanas. Y en cualquier caso, los turcos ya formaban parte del imaginario popular en España, gracias a un interés renovado por el tema tanto en la literatura como en las artes, sobre todo a partir de la Batalla de Lepanto.

\section{Conclusiones}

Las cartas manuscritas redactadas por Mosquera en Madrid, construidas a partir de avisos italianos, impresos en Roma y obtenidos desde la misma frontera del imperio húngaro, pasaban por Sevilla donde eran convertidas en nuevos relatos impresos en castellano, y presumiblemente seguían luego su camino hasta América en su versión manuscrita. Este trasvase desde la forma manuscrita a la impresa es una de las constantes del primer periodismo europeo, como también lo es la interacción entre agentes de muy distinto perfil profesional: el novellante a sueldo de los poderosos; el escritor inserto en redes de clientelismo que escribe a sus superiores como una muestra de vasallaje; el impresor pionero que entrevé las posibilidades del negocio informativo... Como trasfondo, los poderes religiosos y políticos que hacen uso de la fiebre de noticias del público, en su necesidad de mantener una buena reputación.

Bernardino Beccari, en Italia, y Juan de Mosquera, en España, pueden ser considerados pioneros del periodismo en sus respectivas naciones. Estos dos pioneros, en Italia y en España, trabajan casi al mismo tiempo y ritmo; el italiano se adelanta un par de años en la concepción del producto, el español aporta la numeración mediante ordinales que confirma la aparición de un nuevo discurso escrito, el periodístico.

En 1600, justo con la llegada del nuevo siglo, se cierran ambas series periodísticas, la italiana y la sevillana, tan estrechamente relacionadas y pioneras ambas en la historia del periodismo europeo. El tema de las guerras turcas irá declinando en la atención del público, hasta que vuelva a recobrar el primer plano de la actualidad en los años ochenta de este mismo siglo XVII, cuando el Segundo Sitio de Viena resucite el miedo hacia el enemigo secular de los cristianos.

8 Recordemos que la correspondencia viajaba desde Sevilla a América en un correo anual que partía en julio. Por tanto es posible que los ritmos de esta correspondencia se ajustaran a esta práctica, y las cartas hacia América llegaran a Sevilla preferentemente a principios de verano. 
El enfoque microhistórico nos ha permitido desvelar una red internacional de noticias que trabaja con eficacia y celeridad, en los últimos años del siglo XVI. Esta red, y otras muchas trabajando al unísono a lo largo y ancho de Europa, dibujaron en poco tiempo un panorama donde fue posible la aparición de la información periódica, y esta mantuvo durante todo el siglo XVII el carácter pan-europeo con el que la hemos visto nacer en nuestro ejemplo.

\section{Referencias bibliográficas}

AGULLÓ Y COBO, Mercedes (1966): Relaciones de sucesos I: Años 1477-1619. Madrid, CSIC.

ÁLVAREZ MÁRQUEZ, Carmen (2007): La impresión y el comercio de libros en la Sevilla del Quinientos. Sevilla, Secretariado de Publicaciones de la Universidad de Sevilla.

BULGARELLI, Tullio (1966): "Bernardino Beccari da Sacile antesignano dei giornalisti italiani”, Accademie e Biblioteche, XXXIV, pp. 123-135.

BULGARELLI, Tullio (1967): Gli avvisi a stampa in Roma nel Cinquecento. Bibliografia, antología. Roma, Istituto di studi romani.

BULGARELLI, Tullio (1970): Dizionario Biografico degli Italiani, Volumen 7. Consultado en línea (21/09/2012): http://www.treccani.it/enciclopedia/

COELLO DE LA ROSA, Alexandre (2008): "De mestizos y criollos en la Compañía de Jesús (Perú, siglos XVI-XVII)", Revista de Indias, vol. LXVIII, núm. 243, pp. 37-66.

DOMÍNGUEZ GUZMÁN, Aurora (2012): "El preperiodismo en España a finales del Quinientos: las relaciones de sucesos impresas por Rodrigo de Cabrera", en De libros, lecturas y fiestas en la Sevilla áurea. Sevilla, Servicio de Publicaciones de la Universidad de Sevilla, pp. 173-212.

GONZÁLEZ SÁNCHEZ, Carlos Alberto y MAILLARD ÁLVAREZ, Natalia (2003): Orbe tipográfico. El mercado del libro en la Sevilla de la segunda mitad del siglo $X V I$. Gijón, Trea.

INFELISE, Mario (2002): Prima dei giornale. Alle origine della pubblica informazione. Roma, Laterza.

RAYMOND, Joad (2003): Pamphlets and Pamphleetering in Early Modern Britain.Cambridge, Cambridge UniversityPress.

SÁIZ, Ma Dolores (1987): Historia del periodismo en España. Los orígenes. El siglo XVIII. Madrid, Alianza.

URIARTE, José Eugenio de (1906): Catálogo razonado de obras anónimas y seudónimas de autores de la Compañía de Jesús pertenecientes a la antigua asistencia española con un apéndice de obras de los mismos, dignas de especial estudio bibliográfico. Madrid, Establecimiento Tipográfico Sucesores de Rivadeneyra. 